\title{
Stereochemical Control of Peptide Folding
}

\author{
Ramesh Kaul ${ }^{\mathrm{a}}$ and P. Balaram ${ }^{\mathrm{a}, \mathrm{b}, *}$ \\ ${ }^{a}$ Molecular Biophysics Unit, Indian Institute of Science, Bangalore 560 012, India \\ ${ }^{\mathrm{b}}$ Chemical Biology Unit, Jawaharlal Nehru Centre for Advanced Scientific Research, Bangalore 560 012, India
}

\begin{abstract}
Stereochemically constrained amino acid residues that strongly favour specific backbone conformations may be used to nucleate and stabilize specific secondary structures in designed peptides. An overview of the use of $\alpha \alpha$-dialkyl amino acids in stabilizing helical structures in synthetic peptides is presented, with an emphasis on work carried out in the authors laboratory. $\alpha$-Aminoisobutyric acid (Aib) and related achiral homologs facilitate stable helix formation in oligopeptides as exemplified by a large number of crystal structure determinations in the solid state. The ability to design conformationally rigid helical modules has been exploited in attempts to design structurally well characterized helix-linker-helix, using potential nonhelical linking segments. $\beta$ Hairpin design has been approached by exploiting the tendency of 'prime turns' to nucleate hairpin formation. The use of nucleating ${ }^{D}$ Pro-Gly segments has resulted in the generation of several well characterized $\beta$-hairpin structures, including the crystallographic observation of $\beta$-hairpin in a synthetic apolar octapeptide. Extensions of this approach to three stranded $\beta$-sheets and larger structures containing multiple DPro-Gly segments appear readily possible.
\end{abstract}

\section{Introduction}

The rich diversity of 3-dimensional folds in protein structures is generated using very few elements of secondary structure, like helices, strands, and turns that are connected by irregular loops and packed together in a compact fashion. ${ }^{1,2}$ A precise relationship between protein sequence and 3-dimensional structure is still to be firmly established. However, the enormous activity in the area of protein structure and folding has provided many powerful insights into the determinants of secondary and tertiary folding in polypeptide sequences. ${ }^{3,4}$ The construction of designed sequences with predictable folding patterns is a critical test of our understanding of the principles that relate amino acid sequence to the polypeptide 3-dimensional structure. De novo design approaches have been intensively investigated over the past decade leading to notable successes in the area of construction of helical bundles ${ }^{5-9}$ and metal binding motifs. ${ }^{10-13}$ The design of $\beta$-sheet proteins from first principles has been less successful partly because of practical difficulties associated with the limited solubilities of designed polypeptide sheets. ${ }^{14-18}$ Most approaches to de novo design address the problem of constructing a water soluble structure as a protein mimic. The heart of these strategies involves choice of

Key words: Peptide conformation; stereochemically constrained amino acids; helical peptides, helix-helix motif; $\beta$-hairpin, $\alpha$-aminoisobutyric acid; $\alpha \alpha$-dialkylglycine, D-proline.

*Corresponding author. Fax: +91-80-3341683; e-mail: pb@mbu.iisc. ernet.in sequences that favour a specific secondary structure (for example, helix or strand) followed by a reliance on the dominant role of hydrophobic interactions in generating compact super-secondary structural motifs. The success of these strategies is then based on a patterning of hydrophobic and polar residues along the sequence, in order to generate amphipathic secondary structure elements. ${ }^{19-21}$ In some cases the use of appropriately positioned liganding groups permits metal ion directed assembly. ${ }^{22-25}$ A novel approach to assembly of secondary structures is based on covalent attachment of multiple polypeptide chains to a suitable template leading to the concept of template assisted synthetic protein (TASP). ${ }^{26-28}$ In most approaches, the choice of sequences is based on secondary structure propensities derived from analysis of protein crystal structures..$^{29,30}$

A completely different approach to synthetic protein design involves stabilization of specific secondary structures by the use of stereochemically constrained nonprotein amino acids ${ }^{31}$ or by the use of synthetic templates, which permit nucleation of helices, ${ }^{32,33}$ or sheets. ${ }^{34-38}$ In these cases, the designed peptides are often soluble in organic solvents, with folding being primarily driven by local stereochemical influences. This overview examines the use of stereochemically constrained amino acid residues in directing polypeptide chain folding.

Polypeptide chain conformations are determined by the two degrees of torsional freedom about $\mathrm{N}-\mathrm{C}^{\alpha}(\phi)$ and 
$\mathrm{C}^{\alpha}-\mathrm{C}^{\prime} \mathrm{O}(\psi)$ bonds (Fig. 1). The torsional angle about the peptide bond $\mathrm{C}^{\prime}-\mathrm{N}$ is restricted to either $180^{\circ}$ (trans) or $0^{\circ}(\mathrm{cis})$, with the former being overwhelmingly predominant in peptide and protein structures. The diverse backbone conformations assumed by polypeptide chains in proteins is then a consequence of the nature of the $\phi, \psi$ values at individual residues. The seminal work of Ramachandran and co-workers established that stereochemically allowed backbone conformations were largely determined by simple van der Waals criteria, which precluded nonbonded atoms from coming closer than specified 'contact limits'. ${ }^{39-41}$ Figure 2 shows the Ramachandran (contact) map for the Gly residue, which contains two hydrogen atoms bonded to the tetrahedral $\mathrm{C}^{\alpha}$ atom. Almost $60 \%$ of conformational space is stereochemically allowed for the Gly residue. Figure 2(b) shows the Ramachandran map for the L-Ala residue demonstrating that replacement of hydrogen at the $\mathrm{C}^{\alpha}$ atom by a methyl group results in a dramatic shrinking of the allowed regions of $\phi, \psi$ space. Most noteworthy, is the fact that for the L-Ala residue allowed values of $\phi$ are almost invariably negative, with only a small region of positive values being allowed in

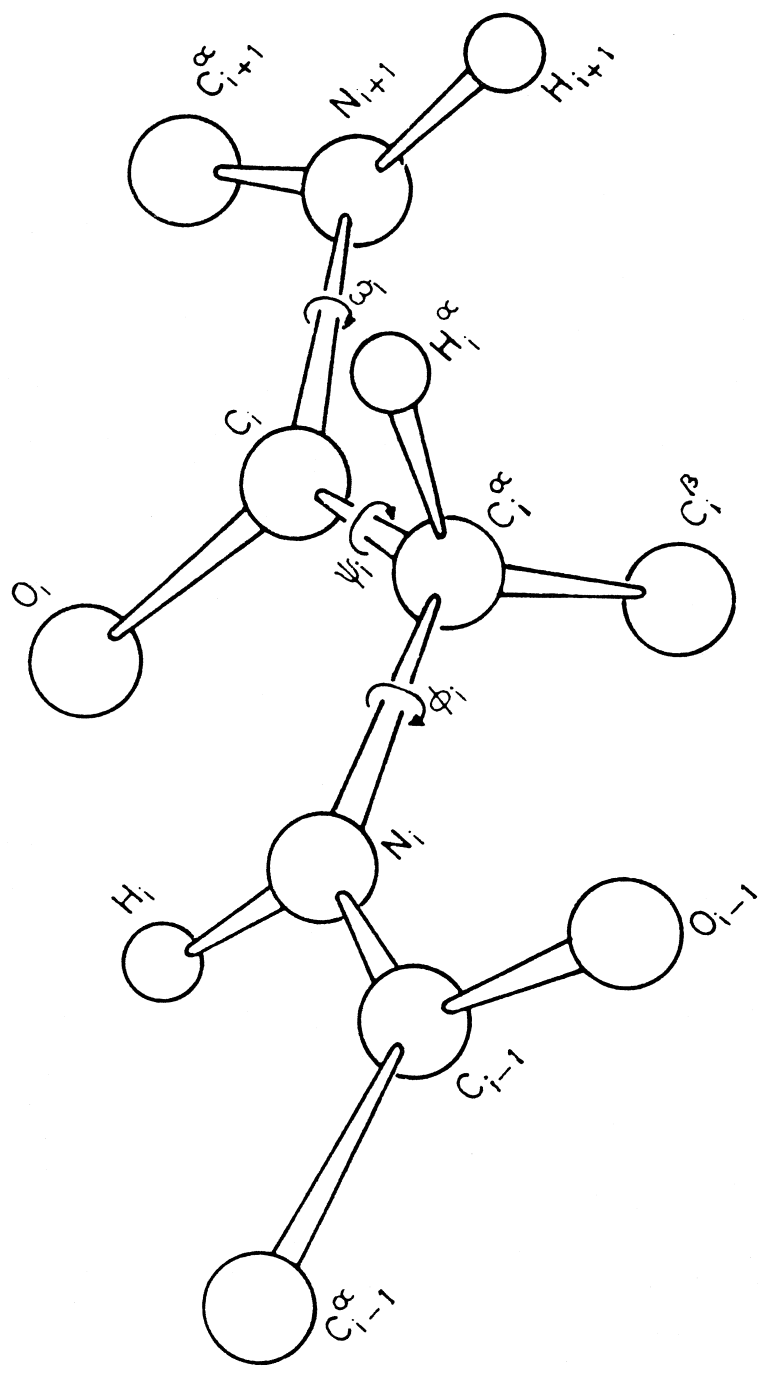

Figure 1. Ball and stick representation of a dipeptide unit. The dihedral angles $\phi, \psi$ and $\omega$ are marked. the right handed top quadrant of the $\phi, \psi$ map. Figure 3 illustrates the superposition of Ramachandran maps for L-Ala and D-Ala residues, which are precisely related by inversion about the origin. It is immediately apparent that only a very small region of $\phi, \psi$ space is allowed for both L-Ala and D-Ala residues. Clearly, subsititution of the $\alpha$-hydrogen in L-Ala by a methyl group should lead to an achiral residue in which the Ramachandran allowed regions are limited to those shown in Figure 4. $\alpha, \alpha$-Dialkyl amino acid residues should therefore be extremely conformationally restricted, with allowed conformations lying largely in the region $\phi \pm 60^{\circ}, \psi \pm 30^{\circ}$. This line of reasoning first led Ramachandran and Chandrasekaran ${ }^{42}$ in 1970 to suggest that the $\alpha$-aminoisobutyryl residue (Aib, $\alpha$-methylalanyl, $\alpha, \alpha$-dimethylglycyl) would be a conformationally restricted residue favouring helical conformations. Concurrently, Marshall and Bosshard, ${ }^{43}$ using conformational energy calculations suggested that Aib residues should favour helical $\phi, \psi$ values. Shortly thereafter Burgess and Leach on the basis of PCILO calculations suggested that Aib is an obligatory helical residue. ${ }^{44}$ The occurrence of Aib residues in diverse fungal polypeptides and the remarkable membrane channel forming properties exhibited by alamethicin, and related natural peptides, stimulated considerable synthetic and conformational work on Aib containing peptides. ${ }^{45,46}$ The first crystal structures of acyclic Aib containing peptides provided convincing evidence for the tendency of Aib residues to adopt helical $\phi, \psi$ values ${ }^{47-49}$ In the last two decades, a very large number of Aib containing peptide crystal structures have been determined, which demonstrate an overwhelming tendency of these residues to promote helical conformations $^{50-53}$ (Fig. 5). A cursory review of the Cambridge Data Bank reveals that of the 5127 peptide entries, 132 correspond to crystal structures of Aib peptides. While the overwhelming majority of peptide crystal structures are of short sequences less than 6 residues in length, there are many examples of crystalline Aib containing oligopeptides in the size range 7-16 residues. Interestingly, while small proteins $\geqslant 50$ residues in length crystallize relatively easily, acyclic oligopeptides in the range of 6-40 residues are much more difficult to crystallize. This has led to a 'grey area' in the crystallographic characterization of polypeptide structures. There are a relatively large number of accurate structure determinations of short peptides and a growing body of structural information on large proteins; but paradoxically structural information on intermediate size peptides is meagre. Many important biologically active peptides fall into this class. The incorporation of stereochemically constrained aminoacids facilitates crystallization of longer sequences. The abundance of crystallographic data on relatively long Aib peptides is testimony to their ready crystallizability; a feature that is undoubtedly linked to their limited conformational heterogeneity in solution coupled to the decided advantages in packing cylindrical helical molecules into crystals. ${ }^{54}$ The ability of Aib residues to nucleate and stabilize helical conformations in oligopeptides is illustrated by the observation of helical structures in crystals of heptapeptides containing a single Aib residue. ${ }^{55,56}$ 
(a)

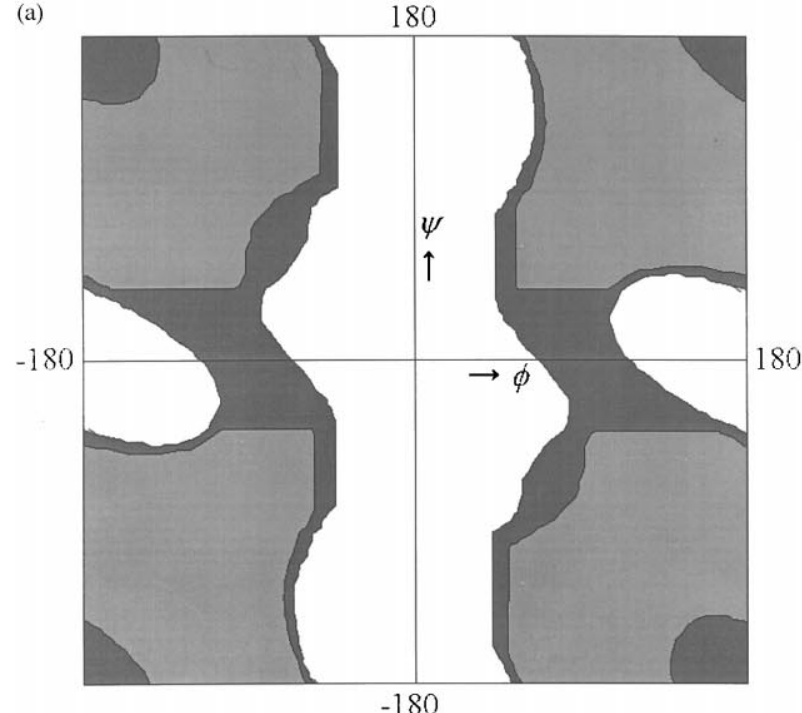

(b)

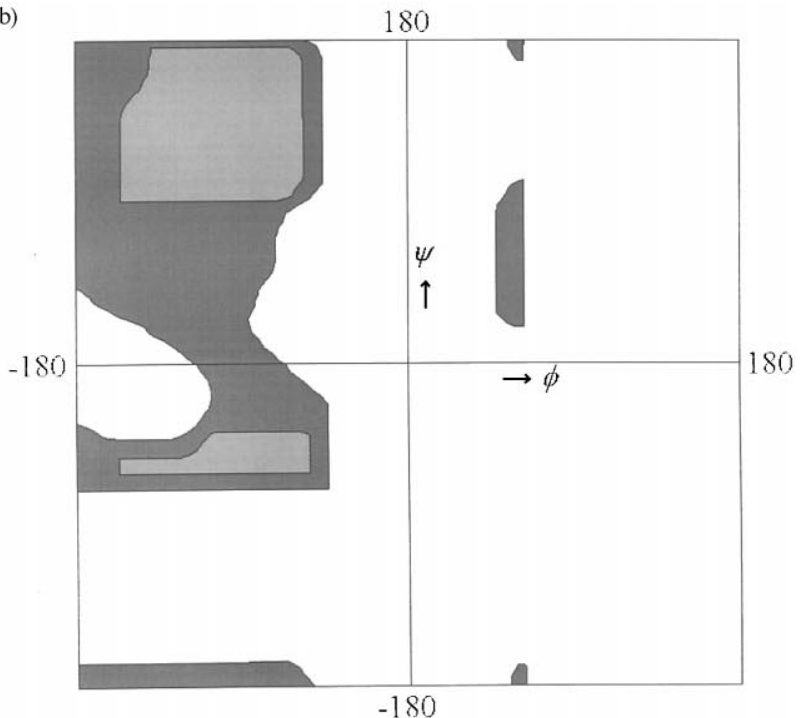

Figure 2. The Ramachandran map for the $N$-acetyl- $N^{\prime}$ methylamide of (a) glycine (b) L-alanine. The dark shaded area corresponds to the fully allowed region and the light shaded zone encloses partially allowed regions.

Interestingly, the conformational constraints imposed by Aib force even proline residues into occupying positions within short helical segments as demonstrated in the crystal structure of Boc-(Val $)_{2}$-Aib-Pro-(Val $)_{3}-\mathrm{OMe} .{ }^{57}$ Figure 6(a) illustrates the crystal state conformation of two 16-residue peptides Boc-(Val-Ala-Leu-Aib) ${ }_{4}-\mathrm{OMe}$ and the natural product [Leu $]^{1}$-zervamicin (Fig. 6(b)), While the former provides an example of approximately four turns of a straight helix, ${ }^{58}$ the latter adopts a curved or bent structure due to the presence of as many as three Pro/Hyp residues in the $\mathrm{C}$-terminus segment. ${ }^{59}$

There has been considerable discussion in the literature on the nature of the helical conformations adopted by Aib rich sequences. ${ }^{51,53,60,61}$ Both $3_{10}$ and $\alpha$-helical conformations have been characterized depending upon peptide length, sequence and Aib content. Several

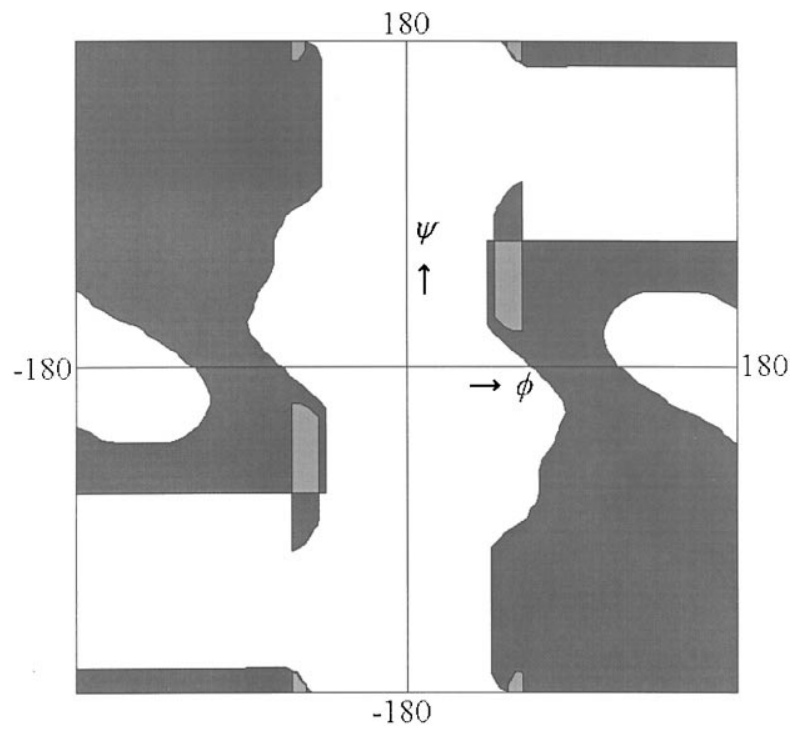

Figure 3. Superposition of the Ramachandran maps for the $N$-acetyl$N^{\prime}$-methylamides of L-alanine and D-alanine. structures of heteromeric sequences containing Aib have revealed mixed $3_{10} / \alpha$-helical structures, ${ }^{51,62,63}$ with the $3_{10}$ segment often occuring at the $\mathrm{N}$-terminus. The $3_{10}$ helix is a structure stabilized by successive $4 \rightarrow 1$ $\mathrm{CO} \ldots \mathrm{NH}$ hydrogen bonds, with idealized $\phi, \psi$ values of $-60^{\circ},-30^{\circ}$ for the right handed screw sense. The $\alpha$-helix is stabilized by successive $5 \rightarrow 1$ hydrogen bonds with idealized $\phi, \psi$ values $-55^{\circ},-45^{\circ}$ for a right handed structure. The distinctions between these two helical types are subtle and involve very small changes in $\phi, \psi$ values. Conformational interconversion between $3_{10}$ and $\alpha$-helices can be easily achieved and have been the subject of several theoretical investigations. ${ }^{64-68}$ Distinctions between these two structures in solution are not readily achieved ${ }^{69}$ although circular dichroism, ${ }^{70,71}$ NMR, ${ }^{72}$ ESR $^{73-75}$ have all been suggested as potential

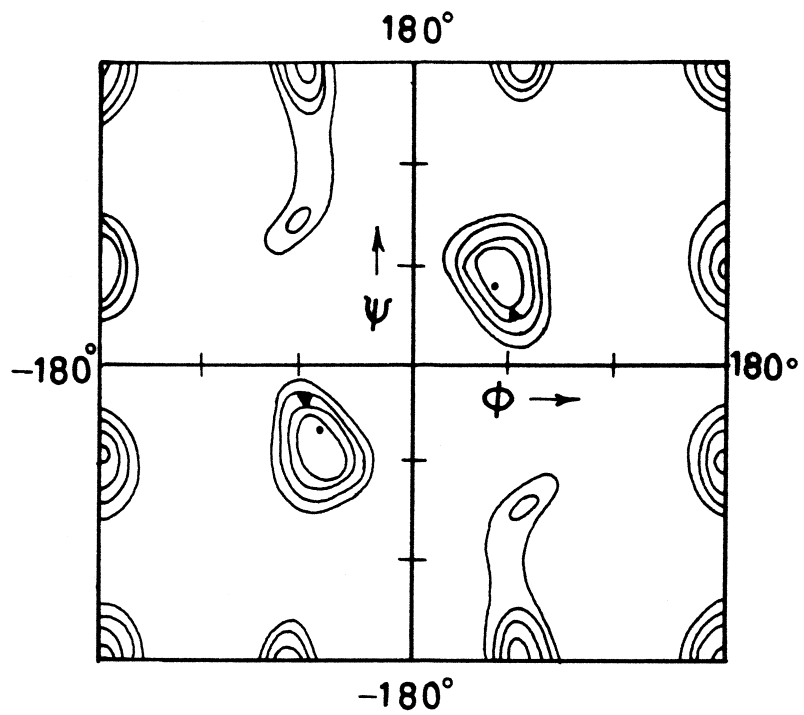

Figure 4. Potential energy map for Ac-Aib-NHMe computed theoretically. The counters are drawn at $1 \mathrm{Kcal} / \mathrm{mol}$ intervals with respect to the innermost contour enclosing the minimum. The ideal $3_{10}(\nabla)$ and $\alpha-$ helical (o) conformations are marked. 


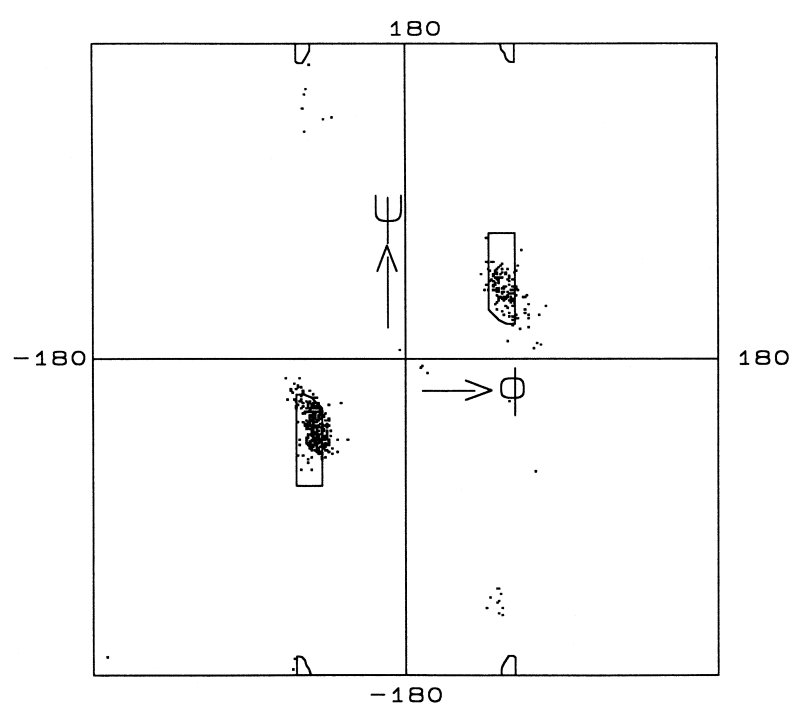

Figure 5. Crystallographically observed $\phi, \psi$ values of Aib residues from 178 independent crystal structures of Aib containing peptides. A total of 534 Aib residues are marked. In the case of achiral peptides crystallizing in a centrosymmetric space group, the sign of the dihedral angles has been chosen arbitrarily.

diagnostic techniques. For purposes of conformational design of protein mimics, a precise distinction between $3_{10}$ and $\alpha$-helical structures is largely unnecessary.

The widely documented ability of Aib to stabilize helical conformations in peptides has been used to construct stereochemically well defined helical modules that can then be assembled into supersecondary structures like helix-helix motifs using appropriate linking segments. This approach constitutes a modular strategy for the construction of synthetic protein mimics and has been termed as a 'Meccano (Lego) Set' approach. ${ }^{31,76}$

\section{Higher homologs of Aib}

Figure 7 illustrates the structures of symmetrical $\alpha, \alpha$ dialkylglycines, which are higher homologs of Aib. Two classes of amino acid residues can be considered, viz, residues with linear alkyl side chains $(\mathrm{Deg}=$ diethylglycine; Dpg $=$ di- $n$-propylglycine; $\mathrm{Dbg}=$ di- $n$-butylglycine) and residues with cycloalkyl side chains (1-aminocycloalkane-1-carboxylic acids, $A_{n} \mathrm{c}$, where $n$ is the number of carbon atoms in the cycloalkane ring). Conformational energy calculations on $\mathrm{Ac}^{-\mathrm{Ac}_{6} \mathrm{c}-\mathrm{NHMe}}$ reveal that the $\mathrm{NH}$ axial conformer is about $1.6 \mathrm{kcal} /$ mole more stable than the $\mathrm{NH}$ equatorial form. Conformational energy maps have been computed for both the axial and the equatorial forms of the $A_{6} \mathrm{c}$ residue (Fig. 8). Pronounced energy minima are located in the right and left handed $33_{10} / \alpha$-helical regions of $\phi, \psi$ space $\left(\phi \sim \pm 60^{\circ}, \psi \sim \pm 30^{\circ}\right) .{ }^{77}$ Crystal structure determinations of short $\mathrm{Ac}_{6} \mathrm{c}$ containing peptides quickly confirmed this expectation. ${ }^{77-79}$ Helical conformations were also demonstrated in structure determinations involving $\mathrm{Ac}_{5} \mathrm{c},{ }^{80,81}$ and $\mathrm{Ac}_{7} \mathrm{c}^{82}$ peptides. The $\mathrm{Ac}_{n} \mathrm{c}$ residues appear predominantly to be limited to helical conformations. The crystal structure of the octapeptide Boc-Leu-Ac $c_{8}$-Ala-Leu-Ac 8 c-Ala-Leu-Ac c c-OMe provides an example of a relatively long helical segment containing pendent cyclooctane rings on one helical face (Fig. 9) (Datta, S.; Shamala, N.; Vijayalakshmi, S.; Rao, R. B.; Balaram, P. unpublished). In contrast to the $\mathrm{Ac}_{n} \mathrm{c}$ residues, theoretical calculations suggest that for the linear dialkyl glycines (Dxg) fully extended conformation $\left(\phi \sim \psi \sim 180^{\circ}, C_{5}\right)$ are energetically slightly more favourable than folded helical conformations. ${ }^{83-85}$ Indeed, crystal structures of short homooligopeptides ranging in length up to 5 residues yielded fully extended $\mathrm{C}_{5}$ conformations in crystals. ${ }^{86,87}$ However, many recent crystal structure determinations of Dpg and Dbg containing peptides have yielded helical conformations. In short heteromeric sequences, both folded and extended Dpg conformations have been characterized. For example, in the chemotactic tripeptide analogue For-MetDpg-Phe-OMe the Dpg residue adopts an extended conformation. $\left(\phi \sim 173^{\circ} \psi \sim 179^{\circ}\right) .{ }^{88}$ In crystals of the tripeptide Boc-Leu-Dpg-Val-OMe (Fig. 10) two independent molecules are observed in the crystallographic asymmetric unit with one adopting helical $\phi, \psi$ values $\left(\phi=62.8^{\circ}, \psi=39.6^{\circ}\right)$ and the other taking up an extended conformation $\left(\phi \sim 176^{\circ}, \psi \sim-180^{\circ}\right)$. $^{89}$ Interestingly even in the homotripeptide Tfa-(Dpg) $)_{3}-\mathrm{DBH}(\mathrm{DBH}=$ $N, N$ (-dibenzyl-hydrazide), all the three Dpg residues adopt helical $\phi, \psi$ values. ${ }^{90}$ Recent studies from our laboratory have attempted to probe the effect of local sequence variations on Dpg residue conformation. ${ }^{91-95}$ Even in the context of flanking Gly residues, which have a low helical propensity, helical conformations have been observed in the 14-residue peptides Boc-ValVal-Ala-Leu-Gly-Dpg-Gly-Val-Ala-Leu-Aib-Val-Ala-LeuOme. ${ }^{96}$ It is noteworthy that in the tripeptide Boc-GlyDpg-Gly-OH, the Dpg residue adopts an extended conformation, in contrast to the conformation of this segment in the longer peptide. ${ }^{96}$

The body of accumulated evidence suggests that helical conformations are likely to be favoured at the Dpg residues in long heteromeric sequences. Fully extended and helical conformations at Dxg residues appear to be characterized by distinctly different bond angles $\left(\mathrm{N}-\mathrm{C}^{\alpha}-\mathrm{C}, \tau\right)$ at the tetrahedral $\mathrm{C}^{\alpha}$ atom. Values between $101^{\circ}$ and $105^{\circ}$ are noted for fully extended conformations, while values between $105^{\circ}$ and $113^{\circ}$ are seen for helical conformations. The dependence of conformational energies on the bond angle $\tau$ has previously been established by theoretical calculations. ${ }^{85}$ Two crystal structures of a heptapeptide sequence containing a single centrally located Dpg residue Boc/Ac-Val-Ala-LeuDpg-Val-Ala-Leu-OMe reveal helical conformations. Comparison of the helix stabilities of helical peptide Boc-Val-Ala-Leu-Xxx-Val-Ala-Leu-OMe $(\mathrm{Xxx}=\mathrm{Ac} 8 \mathrm{c}$, $\mathrm{Ac}_{7} \mathrm{c}$, Aib, Deg, Dpg) suggest that the Dxg containing helices are more prone to solvent invasion and unravelling in strongly solvating media (Vijayalakshmi, S.; Rao, R. B.; Karle, I. L.; Balaram, P. unpublished). The higher homologs of Aib with both linear and cycloalkyl side chains may be used to impose severe conformational restraints on the peptide backbone. The tendency of these residues to adopt 'local helical' conformations may be exploited in the design of $\beta$-turns in short peptides. The ability to vary the bulk of the hydrophobic side chains at the $i+1 / i+2$ positions of $\beta$-turns has 


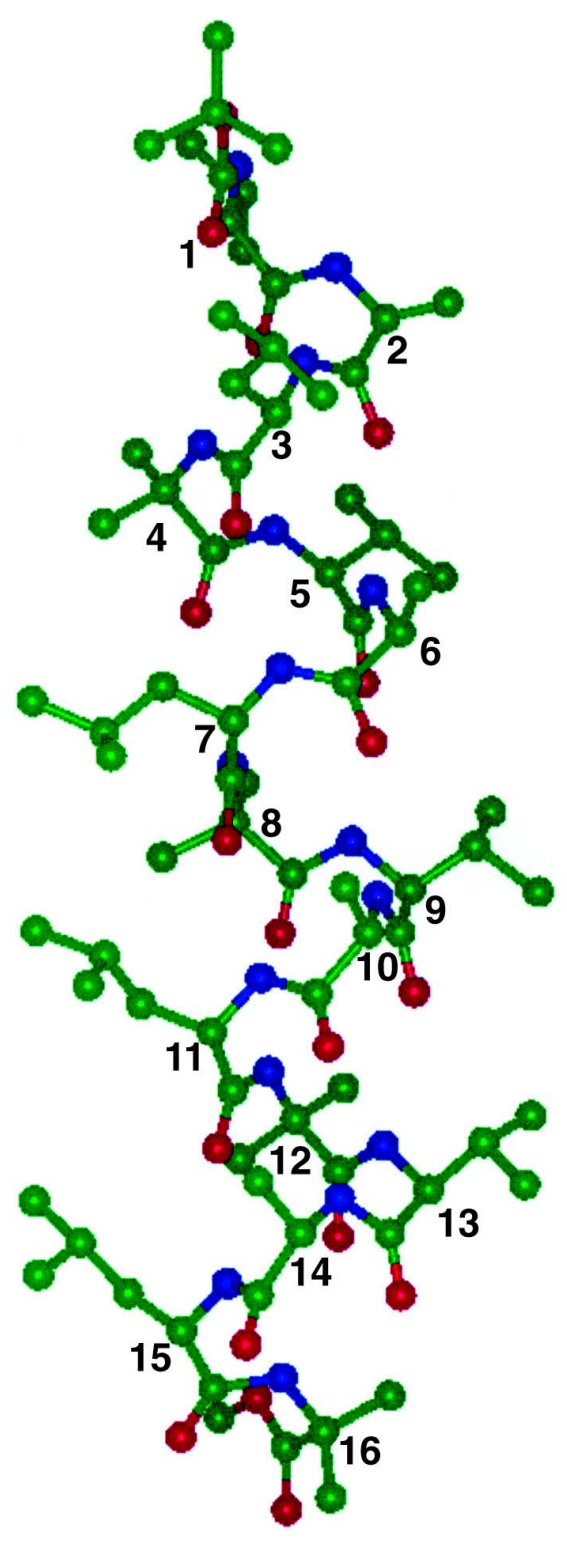

(a)

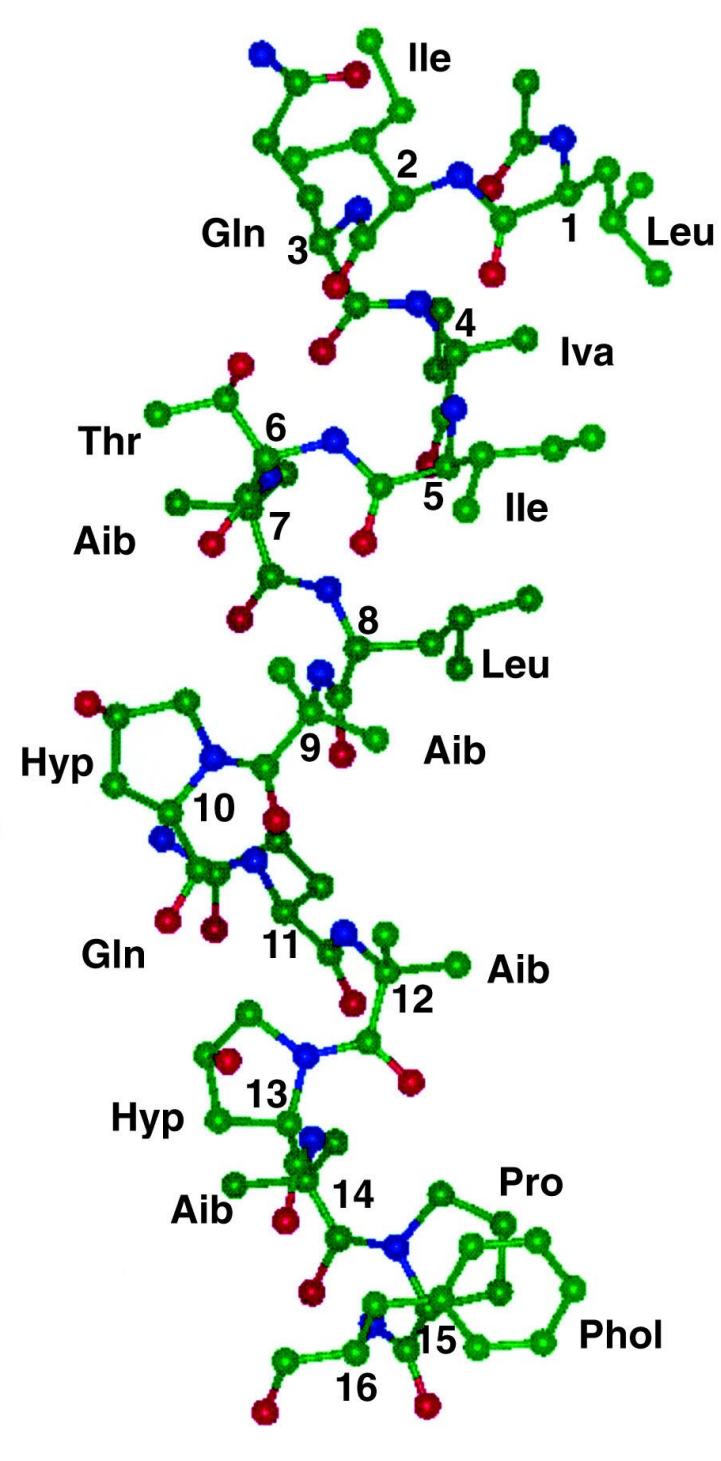

(b)

Figure 6. (a) Crystal structure of Boc-(Val-Ala-Leu-Aib) $)_{4}-\mathrm{OMe}$ showing a 'straight helix'. The $\mathrm{C}^{\alpha}$ atoms are numbered. (b) Crystal structure of $[\mathrm{Leu}]^{1}$-Zervamicin. The helical structure is amphiphilic with all polar moieties on the convex side of the bent helix. Bending is a consequence of the alternating (Aib-Pr0/Hrp) $)_{3}$ sequence at the $\mathrm{C}$-terminus.

been used to probe structure activity relationships for chemotactic peptide analogues binding to the formyl peptide receptor on neutrophils. ${ }^{97}$ In summary Aib and related diakylglycines, are powerful stabilizers of helical conformations permitting the design of well characterized helical molecules.

\section{Design of helix-helix motifs}

Prefabricated helical modules may be assembled into helix-linker-helix motifs using nonhelical linking segments. In proteins, helix-helix motifs containing short linker segments (1-5 residues) have been analyzed and specific families of linkers identified on the basis of their $\phi, \psi$ values. ${ }^{98,99}$ Helix orientation is a function of linker conformation. Most attempts at helix-helix motif construction utilize conformationally flexible linkers, with the expectation that appropriate helix orientation can be achieved by suitable interhelix interactions. Most commonly, the design of helical bundles has been approached by utilizing amphiphilic helical sequences so that nonpolar helix faces are brought into close proximity under the influence of hydrophobic driving forces. ${ }^{5-9}$ Helix-helix motifs and helical hairpins have been approached by linking peptide segments with high helix propensities by short polar loops containing amino acids with limited tendencies to adopt helical conformation. Implicit in these strategies is the formation 
<smiles>CC(C)(N)C(=O)O</smiles>

Aib
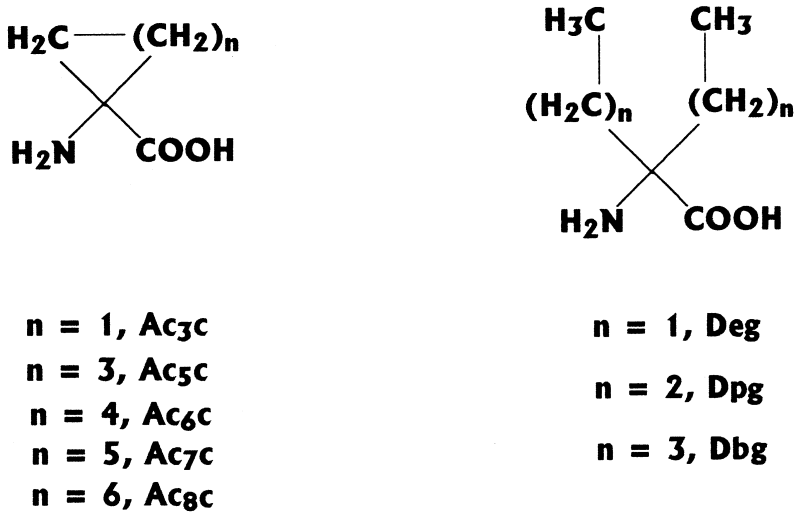

$n=1$, Deg

$\mathrm{n}=2, \mathrm{Dpg}$

n $=3, \mathrm{Dbg}$

Figure 7. Structures of symmetrical $\alpha, \alpha$-dialklglycines.

of a 'hydrophobic core' formed by close interhelix contacts involving nonpolar side chains. ${ }^{100-102}$ In the absence of favourable solvent forces it is necessary that conformational control be exercised over the linking segments or that specific attractive interactions be designed between the helix segments. Several exploratory investigations in this laboratory have been directed towards the design of helix-helix motifs that are soluble in relatively inert organic solvents. The use of short polymethylene chains has been investigated using $\varepsilon$-aminocaproic acid (Acp) linkers. Crystallographic determinations of the structures of two 15-residue peptides Boc-Val-Ala-Leu-Aib-Val-Ala-Leu-Acp-Val-AlaLeu-Aib-Val-Ala-Leu-OMe and Boc -Val-Ala-Leu-AibVal-Ala-Leu-Acp- ${ }^{\mathrm{D}}$ Val- ${ }^{\mathrm{D}} \mathrm{Ala}-{ }^{\mathrm{D}} \mathrm{Leu}-\mathrm{Aib}-{ }^{\mathrm{D}}$ Val- ${ }^{\mathrm{D}} \mathrm{Ala}-{ }^{\mathrm{D}} \mathrm{Leu}-$ OMe have revealed an extended arrangement of the two helical segments with an interhelical angle close to $180^{\circ} .{ }^{103,104}$ Limited evidence based on interaction with hydrophobic reverse phase C18 columns suggests that these peptides adopt more compact structures in solution. $^{76}$ A detailed study of an analogue peptide BocMet-Ala-Leu-Aib-Val-Ala-Acp-Val-Ala-Leu-Aib-ValAla-Phe-OMe has provided evidence for a folded Ushaped arrangement of the two helices in an apolar solvent like chloroform. ${ }^{105}$ The use of D-residues as potential helix breakers has been investigated in the sequences Boc-Val-Ala-Leu-Aib-Val-Ala-Leu-DPhePro-Val-Ala-Leu-Aib-Val-Ala-Leu-OMe and Boc-Val-

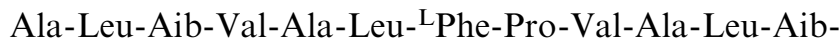
Val-Ala-Leu-OMe. Despite the presence of a centrally located DPhe-Pro segment, a continuous helix has been inferred in the 16-residue peptide from NMR studies. ${ }^{106}$ An extension to three residue linkers has been attempted in the sequence Boc-Leu-Aib-Val-AlaLeu-Aib-Val-DVal-LPhe-DPro-Val-Ala-Leu-Aib-Val-AlaLeu-OMe. In this sequence, the two helical segments encompassing residues 1-7 and 11-17 have been conformationally characterized in crystals of the corresponding Boc-protected heptapeptide methyl esters. The incorporation of ${ }^{\mathrm{D}} \mathrm{Val}$ and ${ }^{\mathrm{D}}$ Pro into the three residue linking segment necessarily impedes continuous helix formation. Specifically, DPro is restricted to $\phi$ $+60^{\circ} \pm 20^{\circ}$, which is incompatible with its insertion into a right handed helix $\left(\phi-60^{\circ} \psi-30^{\circ}\right)$. Further, the absence of an $\mathrm{NH}$ group in DPro limits the hydrogen network preventing incorporation of ${ }^{\mathrm{D}} \mathrm{Val}$ into a continuous helix. A central LPhe residue was introduced as an NMR spectroscopic marker and also to facilitate the

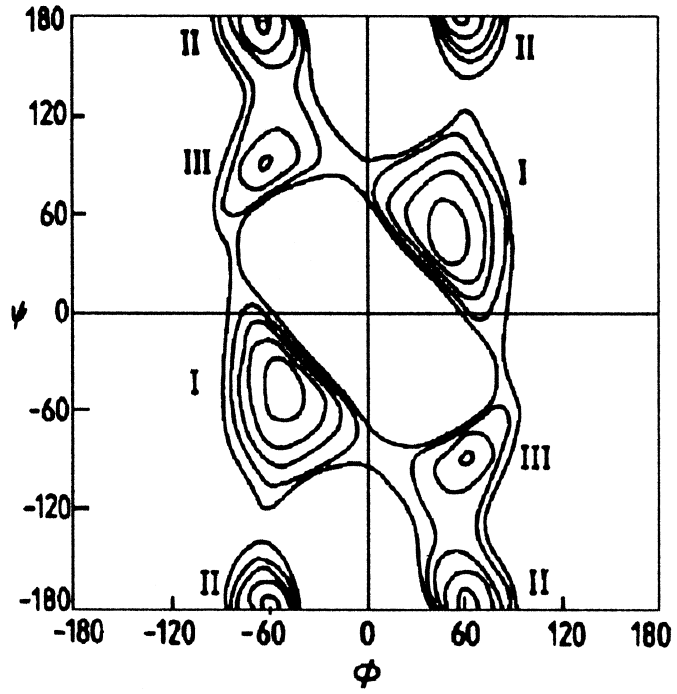

a

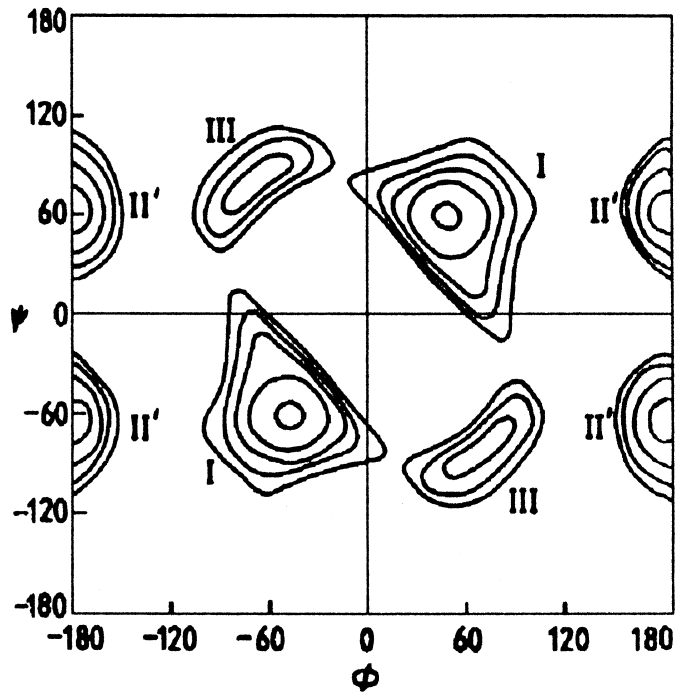

b

Figure 8. Conformational energy maps for Ac-Ac6c-NHMe (a) -NH-axial, (b) -NH-Equatorial. 

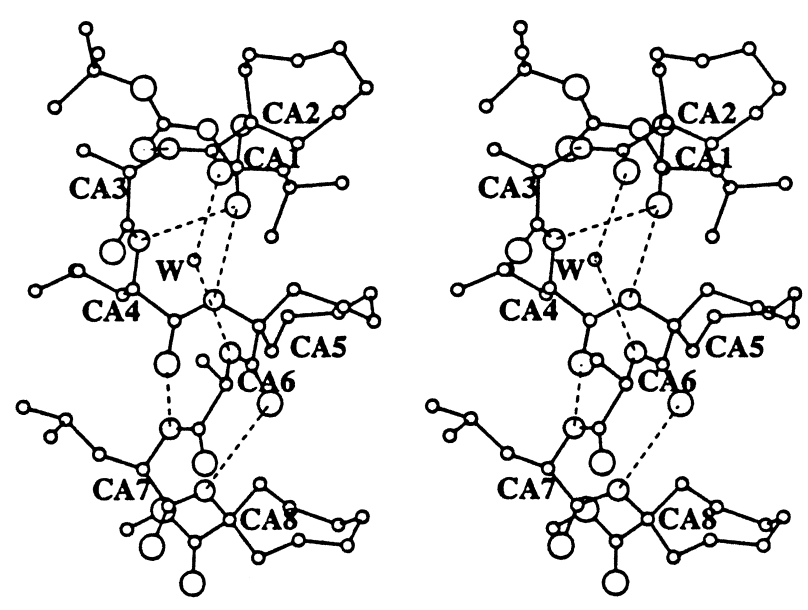

Figure 9. Stereoview of the octapeptide Boc-Leu-Ac ${ }_{8} \mathrm{c}-\mathrm{Ala}-\mathrm{Leu}-\mathrm{Ac}_{8} \mathrm{c}-$ Ala-Leu-Ac $c_{8} \mathrm{c}-\mathrm{Ala}-\mathrm{Leu}-\mathrm{Ac}_{8} \mathrm{c}-\mathrm{OMe}$ in crystals showing three pendent cyclooctane rings. The $\mathrm{C}^{\alpha}(\mathrm{CA})$ atoms are labelled.

formation of a type II $\beta$-turn involving ${ }^{\mathrm{L}} \mathrm{Phe}-\mathrm{D}$ Pro residues, which should then orient the two helical segments in an approximately antiparallel fashion. A common helix terminating motif in proteins involves local reversal of helix sense resulting in the formation of a $6 \rightarrow 1$ hydrogen bond at the C-terminus, termed as the Schellmann motif. ${ }^{107-110}$ In the case of short synthetic peptides the terminating residue has invariably been the achiral residue Aib, ${ }^{111,112}$ whereas in proteins Gly is most frequently found. ${ }^{113}$ In the case of the DVal${ }^{\mathrm{L}}$ Phe- ${ }^{\mathrm{D}}$ Pro linker, inversion of configuration at residue 8 ( ${ }^{\mathrm{D}} \mathrm{Val}$ ) should facilitate Schellmann motif formation and consequent helix termination with ${ }^{\mathrm{D}}$ Val adopting a left handed helical $\left(\alpha_{\mathrm{L}}\right)$ conformation. The residue 9 (LPhe) can be assigned either $\alpha$ or $\beta$ conformations. The residue 10 (DPro) is restricted to values of $+60^{\circ},-120^{\circ}$ $\left(\beta_{\mathrm{L}}\right)$ or $+60^{\circ},+30^{\circ}\left(\alpha_{\mathrm{L}}\right)$. Figure 11 illustrates the relative orientation of two helical segments for four distinct stereochemical alternatives for the linking tripeptide segments. Clearly, two orientations correspond to relatively compact close packed arrangement

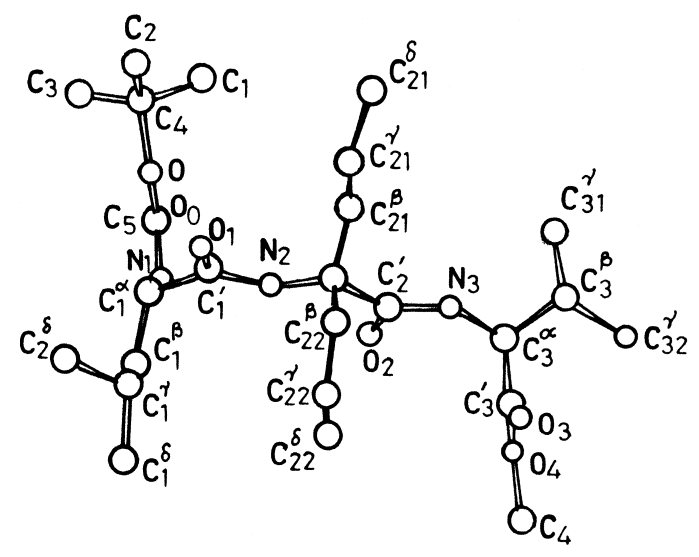

a of the two helices. One of the two compact arrangements involves type II $\beta$ turn formation at the LPheDPro segment, which would bury the Val (11) NH in an intramolecular $4 \rightarrow 1$ hydrogen bond. Interestingly, NMR studies on the 17 residue peptide in $\mathrm{CDCl}_{3}$ suggests that Val (11) NH is shielded from the solvent as evidenced by its inaccessibility to perturbing reagents like DMSO and the free radical 2,2,6,6-tetramethylpiperidinyl-1-oxyl (TEMPO). Unfortunately, this peptide has proved recalcitrant to crystallisation (Kaul, R.; Balaram, P. unpublished).

\section{$\beta$-Hairpin design}

$\beta$-Hairpins may be considered as the simplest element of supersecondary structure amenable to synthetic design. In $\beta$-hairpins two extended strands are brought together to form an antiparallel $\beta$-sheet structure via a nucleating $\beta$-turn (Fig. 12). Analysis of $\beta$-hairpins in protein crystal structures have revealed that a very sizable fraction of these structures incorporate type $\mathrm{I}^{\prime}$ or type $\mathrm{II}^{\prime} \beta$ turns as the nucleating segment. ${ }^{114-117}$ These two types of turns are conformationally defined as follows: type $\mathrm{I}^{\prime}$ $\left(\phi_{\mathrm{I}+1}=60^{\circ}, \psi_{\mathrm{i}+1}=30^{\circ} ; \phi_{\mathrm{i}+2}=90^{\circ}, \psi_{\mathrm{I}+2}=0^{\circ}\right)$, type $\mathrm{II}^{\prime}$ $\left(\phi_{i+1}=60^{\circ}, \quad \psi_{i+1}=-120^{\circ} ; \quad \phi_{i+2}=-90^{\circ}, \quad \psi_{i+2}=0^{\circ}\right)$, where $i+1$ and $i+2$ are the turn forming residues. The occurrence of 'prime turns' with one or both residues adopting positive $\phi$ values facilitates registry of the two antiparallel strands. Designed synthetic $\beta$-hairpins must therefore accomodate two simple stereochemical features; (i) a turn segment that is constrained to type II' $^{\prime}$ or $I^{\prime} \beta$-turn conformations and (ii) strand segments that are rich in residues that favour relatively extended conformations $\left(\phi \sim-120^{\circ}, \psi \sim+120^{\circ}\right)$. ${ }^{D}$ Pro is the residue of choice for nucleating type $\mathrm{I}^{\prime} / \mathrm{II}^{\prime}$ conformations since the constraints of pyrrolidine ring formation restricts $\phi^{\mathrm{D}}$ Pro to $+60^{\circ} \pm 20^{\circ}$. These simple considerations have led to the construction of the octapeptide Boc-Leu-ValVal-DPro-Gly-Leu-Val-Val-OMe for which nuclear Overhauser effects and hydrogen bonding studies clearly established a $\beta$-hairpin conformation in solution, ${ }^{118}$

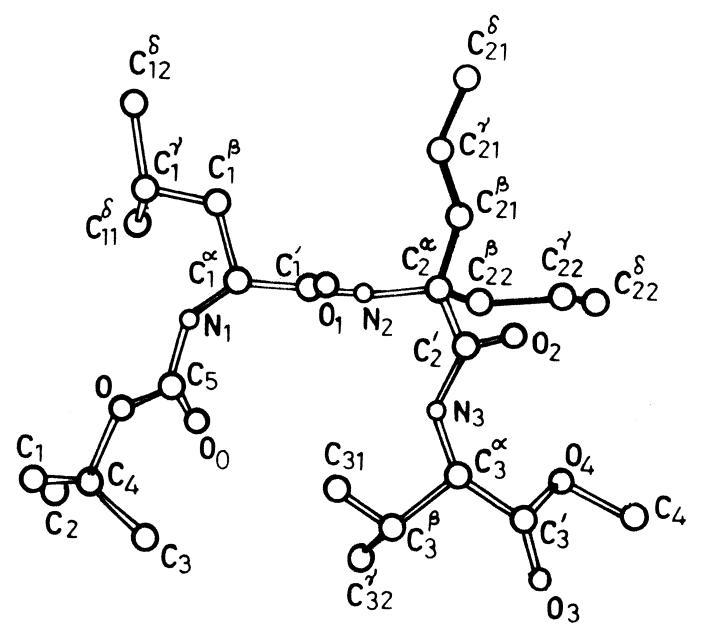

Figure 10. Structures of the two crystallographically independent molecules in crystals of Boc-Leu-Dpg-Val-OMe showing (a) extended Dpg conformation. (b) folded Dpg conformation. 

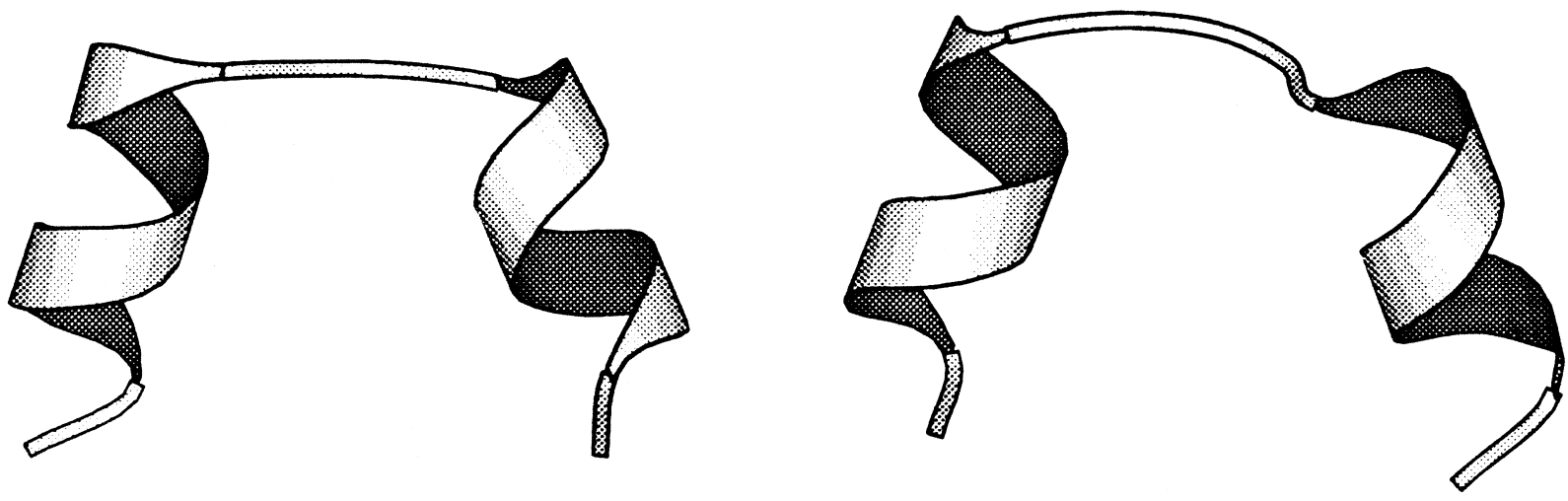

$\begin{array}{cccc}\text { Residues } & 8 & 9 & 10 \\ & \alpha_{L} & \alpha_{R} & \beta_{L}\end{array}$

$\begin{array}{cccc}\text { Residues } & 8 & 9 & 10 \\ & \alpha_{L} & \beta & \alpha_{L}\end{array}$

$\phi\left(^{\circ}\right)$

$\begin{array}{lll}50 & -60 & 60\end{array}$

$\phi\left(^{\circ}\right)$

$\begin{array}{lll}50 & -120 & 50\end{array}$

$\psi\left({ }^{\circ}\right)$

$\begin{array}{lll}50 & -30 & -120\end{array}$

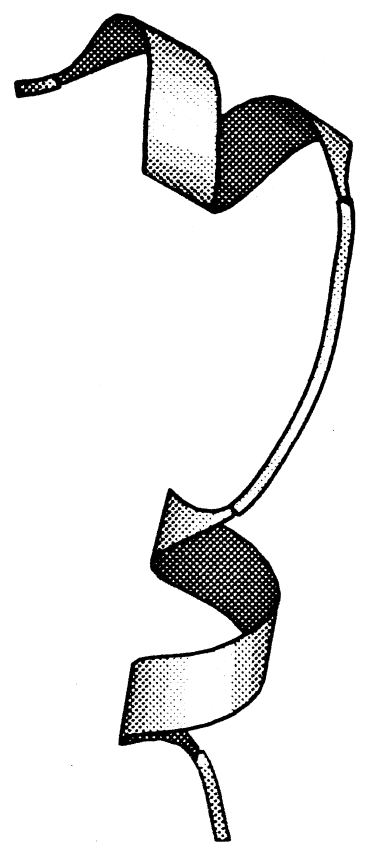

$\psi\left({ }^{\circ}\right) \quad 50 \quad 50 \quad 50$

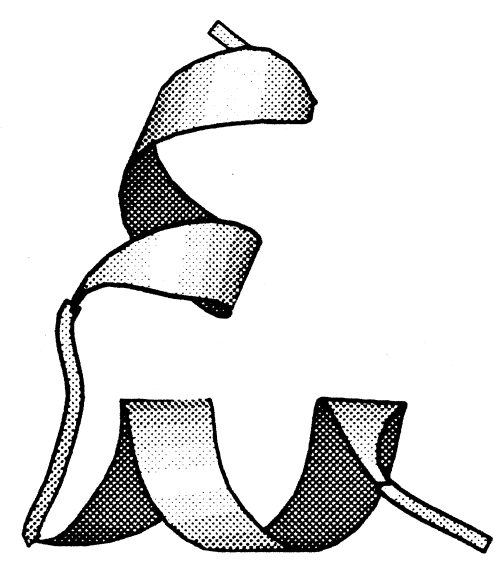

$\begin{array}{cccc}\text { Residues } & 8 & 9 & 10 \\ & \alpha_{L} & \alpha_{R} & \alpha_{L}\end{array}$

$\phi\left({ }^{\circ}\right)$

$\psi\left({ }^{\circ}\right)$

$$
\alpha_{L} \quad \alpha_{R} \quad \alpha_{L}
$$

$$
\begin{array}{lll}
50 & -60 & 60
\end{array}
$$

$\begin{array}{lll}50 & -30 & 30\end{array}$

Residues

89

10

$\begin{array}{lll}\alpha_{L} & \beta_{R} & \beta_{L}\end{array}$

$\phi\left({ }^{\circ}\right)$

$50-120$

60

$\psi\left({ }^{\circ}\right)$

50

$120-120$

Figure 11. Four distinct stereochemical alternatives for a helix-linker-helix peptide, containing two 7-residue helical segments linked by a 3-residue loop (residues 8-10). The backbone conformations at the 3-residues in the linking segments are indicated. Only the $\mathrm{N}-\mathrm{C}^{\alpha}-\mathrm{C}^{\prime}$ backbone is shown. 
which was later confirmed by X-ray diffraction in crystals $^{119}$ (Fig. 13). A detailed comparison by NMR spectroscopy of the octapeptide Boc-Leu-Val-Val-DPro-GlyLeu-Val-Val-OMe and Boc-Leu-Val-Val-LPro-Gly-LeuVal-Val-OMe reveals that the hairpin formation was a specific feature of the DPro containing sequences. ${ }^{120}$ The use of DPro to facilitate $\beta$-hairpin formation is also exemplified in a 23-residue peptide Ac-Tyr-Thr-ValDPro-Ser-Fen-Thr-Phe-Ser-Arg-Ser-Asp-Leu-Ala-LysLeu-Leu-Leu-Arg-Leu-His-Ala-Gly-NH2 having a $\beta \beta \alpha$ architecture of a putative $\mathrm{Zn}$ finger. Here the key step in the design was the replacement of ${ }^{\mathrm{L}} \mathrm{Pro}^{4}{ }_{-}{ }^{\mathrm{D}} \mathrm{Ser}^{5}$ by ${ }^{D} \mathrm{Pro}^{4}-\mathrm{Ser}^{5}$, that is, conversion of a type II $\beta$-turn to a type II' $\beta$-turn, which had the dramatic effect of inducing $\beta$-hairpin conformation in the N-terminal octapeptide segment, thereby stabilizing the tertiary structure of the motif. ${ }^{121,122}$ Folding of small tetrapeptide segments into $\beta$-hairpin loops as a result of introduction of a DPro-X segment instead of ${ }^{\mathrm{L}}$ Pro-X has also been described in the study of model peptides Ac-Val- ${ }^{\mathrm{L}}$ ProGly-Leu-NMe ${ }_{2}$ and Ac-Val-DPro-Gly-Leu-NMe ${ }_{2}{ }^{123}$ Similar observations have been made from the studies on peptide fragments derived from the $\mathrm{N}$-terminal segment of ubiquitin. ${ }^{124}$

Recent studies in this laboratory have extended this approach to the design of synthetic 3-stranded $\beta$-sheet structures. A 14-residue peptide Boc-Leu-Phe-Val-DProGly-Leu-Val-Leu-Ala-DPro-Gly-Phe-Val-Leu-OMe, which contains two centrally located DPro-Gly segments has been shown to form the three-stranded structure illustrated in Figure 14 in $\mathrm{CDCl}_{3}$ solution. ${ }^{125}$ Clear evidence for the postulated conformation is

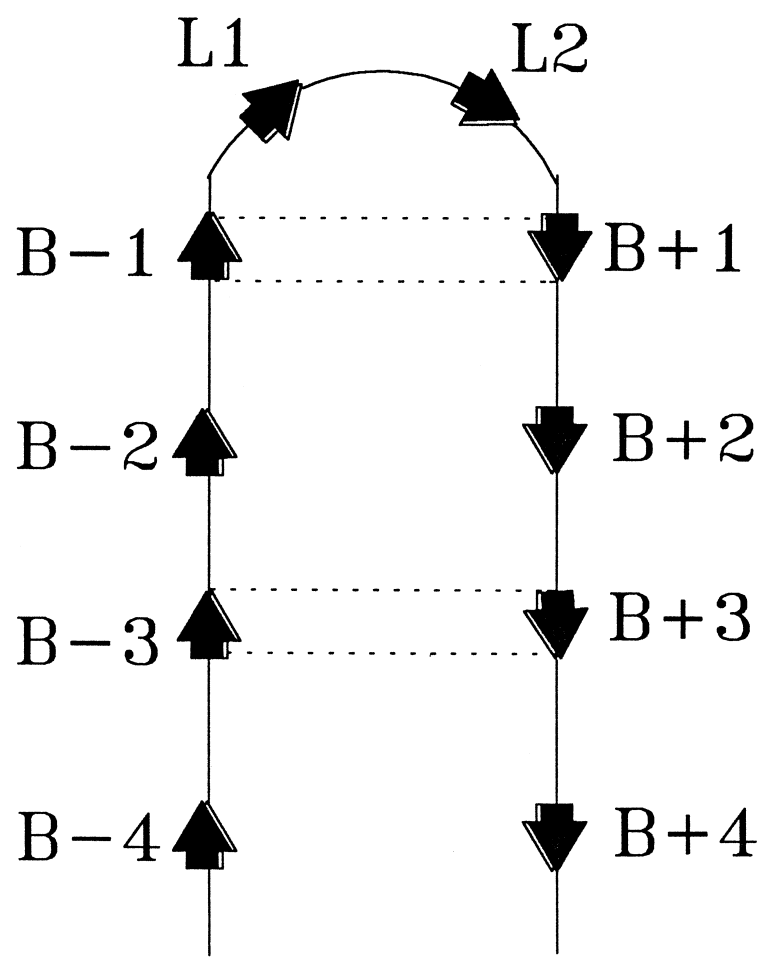

Figure 12. Definition of a two-residue loop $\beta$-harpin. Strand length of 4-residues. The strand and loop positions are designed as $\mathrm{B} \pm \mathrm{X}$ and $\mathrm{L}-$ $\mathrm{X}$, respectively. obtained from backbone-backbone and side chain-side chain interstrand nuclear Overhauser effects, along with complete delineation of intramolecularly hydrogen bonded NH groups. The use of DPro-Gly segments in water soluble peptides has also been shown to facilitate $\beta$-hairpin formation. For example, Serrano et al. (1996) reported a water soluble $\beta$-hairpin Arg-Gly-Ile-Thr-ValAsn-Gly-Lys-Thr-Tyr-Gly-Arg in which NMR studies are consistent with a population of $\sim 35 \%$ of the
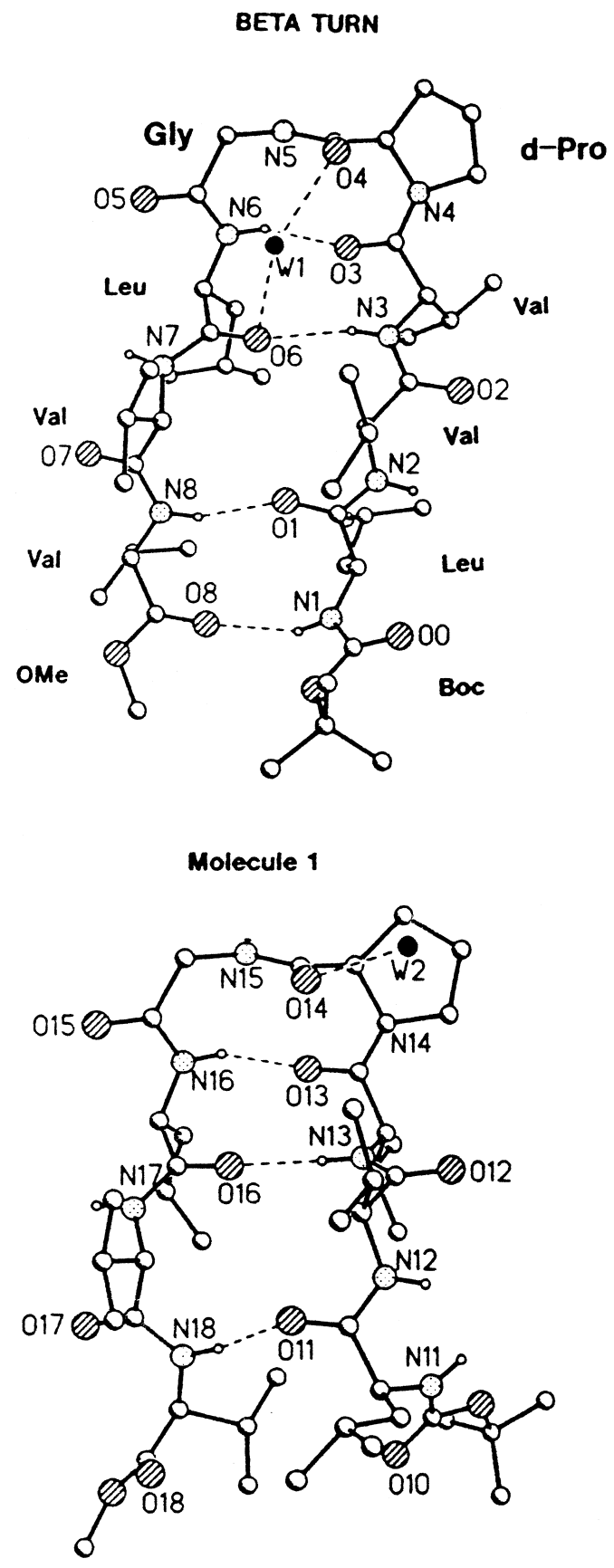

Molecule 2

Figure 13. Crystal structure of the octapeptide Boc-Leu-Val-Val- ${ }^{D}$ ProGly-Leu-Val-Val-OMe showing an almost ideal $\beta$-hairpin structure with a type II $^{\prime} \beta$-bend at ${ }^{D}$ Pro $^{4}-G^{-}{ }^{5}$ for both molecules in the crystallographic assymmetric unit. 


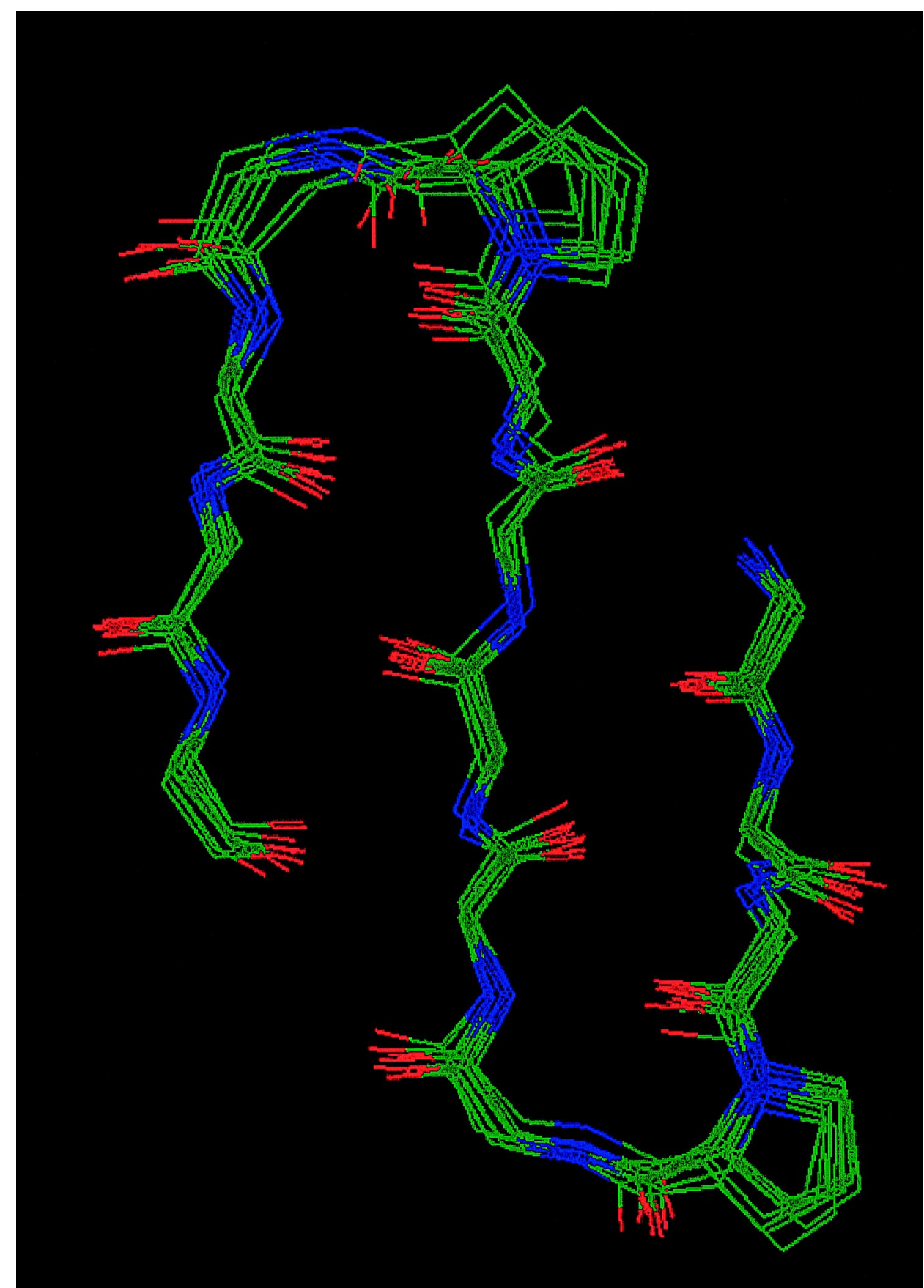

Figure 14. Superposition of a family of ten structures of the 14 residue peptide sequence Boc-Leu-Phe-Val-DPro-Gly-Leu-Val-Leu-Ala- ${ }^{\mathrm{D} P r o-G l y-}$ Phe-Val-Leu-OMe obtained using restrained molecular dynamics with NOE-derived interproton distance constraints.

desired conformation. ${ }^{126}$ Studies in this laboratory on the analogue peptide Arg-Gly-Ile-Thr-Val-DPro-GlyLys-Thr-Tyr-Gly-Arg reveal that the replacement of Asn in the turn segment by ${ }^{D}$ Pro results in a dramatic increase in the population of $\beta$-hairpin structures (unpublished). The superiority of the DPro-Gly segment as a strong $\beta$-hairpin inducer over the Xxx-Gly $\left(\mathrm{Xxx}=\mathrm{Asn},{ }^{\mathrm{L}} \mathrm{Pro}\right)$ segment has been recently shown in a 12-residue peptide Arg-Tyr-Val-Glu-Val-Xxx-Gly-OrnLys-Ile-Leu-Gln. ${ }^{127}$ Special mention must be made of the construction of a three-stranded water soluble $\beta$-sheet structure in a 20 -residue sequence containing two centrally located Asn-Gly turns. ${ }^{128}$ The nucleation of 'prime $\beta$-turns' by incorporation of DPro residues appears to be a powerful means of inducing $\beta$-hairpin conformations. In organic solvents where interstrand hydrogen bonding is a major determinant, both isolated $\beta$-hairpin and multiple hairpins resulting in $\beta$-sheets can be characterized. In aqueous solutions, solvent invasion limits the stabilization afforded by interstrand hydrogen bonding. Thus, although the $\beta$-turn segment may be readily nucleated, extension to stable hairpins and sheets requires building in appropriate sidechain interactions. This successful design of organic solvent soluble three stranded $\beta$-sheet is of relevance in attempts to mimic $\beta$-barrel structures found in bacterial porins. ${ }^{129}$ 


\section{Applications of conformationally constrained peptide modules}

The ability to construct relatively rigid elements of secondary structure, particularly helices, have found varied applications in different areas of chemistry. Kishi and co-workers have attempted to use chiral helices generated using Aib rich sequences along with L-aminoacids as a template for attaching farnesate in order to achieve enantioselective terminal epoxidation; in an attempt to mimic the mechanistic feature of cholesterol biosynthesis. ${ }^{130}$ Rigid helices formed in Aib-rich peptides have proved particularly useful in probing electron transfer mechanisms between donor and acceptor groups that are brought into spatial proximity on the same helix face. ${ }^{131-133}$ Hydrophobic helices formed by alternating (Ala-Aib) $n$ sequences have been used to generate cation binding peptides by means of covalently attached crown ethers. These systems have provided useful information on aggregation and ion-channel formation in lipid bilayer membranes. The ability to easily attach relevant functionalities at the termini of peptides have been exploited in generating biotinylated hydrophobic, helical, Aib containing peptides that have been used to study streptavidin binding at air-water interphases. ${ }^{134,135}$ Cylindrical helical structures readily generated in Aib rich sequences are likely to find many novel applications in material science. Relevant recent reports include the synthesis of monodisperse liquid crystalline peptides based on Aib containing helices ${ }^{136}$ and the formation of self assembling chiral monolayers of helical peptides bound to gold surfaces, in which immobilization is achieved by side chain thioether interaction. ${ }^{137}$

\section{Conclusions}

This article illustrates the use of conformationally constrained amino acid residues like $\alpha \alpha$-dialkylglycines and DPro in generating modules of defined secondary structures. Conformationally constrained residues may be used to advantage in the design of specific folded structures in peptides. The diversity of polypeptide conformations arises due to the sampling of different allowed Ramachandran conformations at individual residues in a polymeric chain. In regular structures the backbone torsional angles lie within a limited region of $\phi, \psi$ space for successive residues. The incorporation of stereochemically constrained residues limits the $\phi, \psi$ values at a specific position in the sequence, thereby acting as a nucleus for formation of regular structures. Nonstandard amino acids with suitable stereochemical properties may therefore be valuable as conformational directors of polypeptide chain folding, permitting the de novo design of novel peptide structures.

\section{Acknowledgements}

We acknowledge long standing collaboration with Isabella L. Karle, N. Shamala and R. Balaji Rao in many of the studies summarized here. The co-workers in this laboratory are acknowledged in the references cited. We are grateful to S. Kumar Singh and K. Gunasekaran for their help in generating some of the figures. Financial support from the Department of Science and Technology is gratefully acknowledged. $\mathrm{RK}$ is a research associate supported by the Department of Biotechnology, Government of India.

\section{References}

1. Orenga, C. A.; Jones, D. T.; Thornton, J. M. Nature (London) 1994, 372, 631.

2. Chothia, C.; Hubbard, T.; Brenner, S.; Barns, H.; Murzin, A. Annu. Rev. Biophys. Biomol. Struct. 1997, 26, 597.

3. Richardson, J. S.; Richardson, D. C. In Prediction of Protein Structure and the Principles of Protein Conformation; Fasman, G. D., Ed.; Plenum: New York, 1989; pp 1-98.

4. Creighton, T. E. Protein Folding; Freeman, W. H. and Co. New York, 1992.

5. DeGrado, W. F. Adv. Protein Chem. 1988, 39, 51.

6. Hecht, M. H.; Richardson, J. S.; Richardson, D. C.; Ogden, R. Science 1990, 249, 884.

7. Bryson, J. W.; Betz, S. F.; Lu, H, S.; Suich, D. J.; Zhou, H. X.; O’Neil, K. T.; DeGrado, W. F. Science 1995, 270, 935.

8. Betz, S. F.; Bryson, J. W.; DeGrado, W. F. Curr. Opin. Struct. Biol. 1995, 5, 457.

9. DeGrado, W. F.; Blake Hill, R. J. Am. Chem. Soc. 1998, 120, 1138 .

10. Regan, L. Annu. Rev. Biophysics Biomol. Struct. 1993, 22, 257.

11. Regan, L. Trends Biochem. Sci. 1995, 280.

12. Klemba, M.; Gardner, K. H.; Marino, S.; Clarke, N. D.; Regan, L. Nat. Struct. Biol. 1995, 2, 368.

13. Cheng, R. P.; Fischer, S. L.; Imperiali, B. J. Am. Chem. Soc. 1996, 118, 11349.

14. Gutte, B.; Daumigen, M.; Wittscheiber, E. Nature (London) $1979,281,650$.

15. Quinn, T. P.; Tweedy, N. B.; Williams, R. W.; Richardson, J. S.; Richardson, D. C. Proc. Natl. Acad. Sci. USA 1994, 91, 8747.

16. Yan, Y.; Erickson, B. W. Protein Sci. 1994, 3, 1069.

17. Roongta, I. E.; Mayo, K. H. Biochemistry 1997, 36, 5245.

18. Smith, C. K.; Regan, L. Acc. Chem. Res. 1997, 30, 153.

19. Kamtekar, S.; Schiffer, J. M.; Xiong, H.; Babik, J. M.; Hecht, M. H. Science 1993, 262, 1680.

20. Xiong, H.; Buckwalter, B. L.; Shieh, H. H.; Hecht, M. H. Proc. Natl. Acad. Sci. USA 1995, 92, 6349.

21. Roy, S.; Ratnaswamy. G.; Bioce, J. L.; Fairman, R.; Mclendon, G.; Hecht, M. H. J. Am. Chem. Soc. 1997, 119, 5302.

22. Ghadiri, M. R.; Choi, C. J. Am. Chem. Soc. 1990, 112, 1630 .

23. Lieberman, M.; Sasaki, T. J. Am. Chem. Soc. 1991, 113, 1470 .

24. Ghadiri, M. R.; Case, M. A. Angew. Chem. Int. Ed. Engl. 1993, 32, 1594.

25. Kohn, W. D.; Kay. C. M.; Sykes, B. D.; Hodges, R. S. J. Am. Chem. Soc. 1998, 120, 1124.

26. Mutter, M.; Vuillemeyer, S. Angew. Chem. Int. Ed. Engl. 1989, 28,535 .

27. Mutter, M.; Tuscherer, G.; Miller, C.; Altman, K. H.; Carey, R. I.; Wyss, D. F.; Labhardt, A. M.; Rivier, J. M. J. Am. Chem. Soc. 1992, 114, 1463.

28. Goodman, M.; Feng, Y.; Melacini, G.; Taulane, J. P. J. Am. Chem. Soc. 1996, $118,5156$.

29. Chou, Y.; Fasman, G. D. Annu. Rev. Biochemistry 1978, 47, 251 .

30. Rost, B.; Sander, C. Curr. Opin. Struct. Biol. 1994, 5, 372.

31. Balaram, P. Curr. Opin. Struct. Biol. 1992, 2, 845. 
32. Kemp, D. S.; Boyd, J. G.; Muendel, C. Nature (London) 1991, 352, 451.

33. Kemp, D. S.; Allen, T. J.; Oslik, L. S. J. Am. Chem. Soc. 1995, 117, 6641 .

34. Tsang, K. Y.; Diaz, H.; Graciani, N.; Kelly, J. W. J. Am. Chem. Soc. 1994, 116, 3988.

35. Nowick, J. S.; Smith, E. M.; Noronha, G. J. Org. Chem. 1995, 60, 7386

36. Schneider, J. P.; Kelly, J. W. J. Am. Chem. Soc. 1995, 117, 2533.

37. Nesloney, C. L.; Kelly, J. W. J. Am. Chem. Soc. 1996, 118, 5836.

38. Nowick, J. S.; Pairish, M.; Lee, I. Q.; Holmer, D. L.; Ziller, J. W. J. Am. Chem. Soc. 1997, 119, 5413.

39. Ramachandran, G. N.; Ramakrishnan, C.; Sasisekharan, V. J. Mol. Biol. 1963, 7, 95 .

40. Ramachandran, G. N.; Sasisekharan, V. Adv. Prot. Chem. 1968, 23, 284.

41. Ramachandran, G. N.; Ramakrishnan, C. Biophys. J. $1965,5,909$

42. Ramachandran, G. N.; Chandrasekaran, R. Progress in Peptide Research. Vol II. (Proceedings of the Second American Peptide Symposium, Cleveland, 1970); Lande, S. Ed; Gordon and Breach: New York, 1972 pp 195-215.

43. Marshall, G. R.; Bosshard, H. E. Circ. Res. 1972, 30/31, 143.

44. Burgess, A. W.; Leach, S. J. Biopolymers. 1973, 12, 2599.

45. Nagaraj, R.; Balaram, P. Acc. Chem. Res. 1981, 14, 356.

46. Mathew, M. K.; Balaram, P. Mol. Cell. Biochem. 1983, 50, 47.

47. Shamala, N.; Nagaraj, R.; Balaram, P. Biochem. Biophys. Res. Commun. 1977, 79, 292.

48. Shamala, N.; Nagaraj, R.; Balaram, P. J. Chem. Soc. Chem. Commun. 1978, 996.

49. Nagaraj, R.; Shamala, N.; Balaram, P. J. Am. Chem. Soc. 1979, 101, 16.

50. Prasad, B. V. V.; Balaram, P. CRC Crit. Rev. Biochem. 1984, 16, 307.

51. Karle, I. L.; Balaram, P. Biochemistry 1990, 29, 6747.

52. Toniolo, C.; Benedetti, E. ISI Atlas of Science: Biochemistry 1988, 225.

53. Toniolo, C.; Benedetti. E. Trends Biochem. Sci. 1991, 16, 350.

54. Karle, I. L. Acta. Cryst. 1992, B48, 341.

55. Karle, I. L.; Flippen-Anderson, J. L.; Sukumar, M.; Balaram, P. Proteins: Struct., Funct., Genet. 1992, 12, 324.

56. Karle, I. L.; Flippen-Anderson, J. L.; Uma, K.; Balaram, P. Biopolymers 1993, 33, 827.

57. Karle, I. L.; Flippen-Anderson, J. L.; Uma, K.; Balaram, H.; Balaram, P. Biopolymers 1990, 29, 1433.

58. Karle, I. L.; Flippen-Anderson, J. L.; Uma, K.; Sukumar, M.; Balaram, P. J. Am. Chem. Soc. 1990, 112, 9350.

59. Karle, I. L.; Flippen-Anderson, J. L.; Agarwalla, S.; Balaram, P. Proc. Natl. Acad. Sci. USA 1991, 88, 5307.

60. Marshall, G. R.; Hodgkin, E. E.; Langs, D. A.; Smith, G. D.; Zabrocki, J.; Leplawy, M. T. Proc. Natl. Acad. Sci. USA 1990, 87, 487.

61. Karle, I. L.; Flippen-Anderson, J. L.; Uma, K.; Balaram, P. Curr. Sci. 1990, 59, 875.

62. Pavone, V.; Benedetti, E.; DiBlasio, B.; Pedone, C.; Santini, A.; Bavoso, A.; Toniolo, C. Crisma, M. J. Biomol. Struct. Dyn. 1989, 7, 1321.

63. Otoda, K.; Kitagawa, J.; Kimura, S.; Imanishi, Y. Biopolymers 1993, 33, 1337.

64. Hodgkin, E. E.; Clarke, J. D.; Miller, K. R.; Marshall, G. R. Biopolymers 1990, 32, 621.

65. Huston, S. E.; Marshall, G. R. Biopolymers 1994, 34, 75. 66. Basu, G.; Kitao, A.; Hirata, F.; Go, N. J. Am. Chem. Soc. 1994, 116, 6307 .
67. Rives, J. T.; Maxwell, D. S.; Jorgenson, W. L. J. Am. Chem. Soc. 1993, 115, 11590 .

68. Zhang, L.; Hermans, J. J. Am. Chem. Soc. 1994, 116, 11915.

69. Sudha, T. S.; Vijayakumar, E. K. S.; Balaram, P. Int. J. Pept. Protein Res. 1983, 22, 464.

70. Toniolo, C.; Polese, A.; Formaggio, F.; Crisma, M.; Kamphius, J. J. Am. Chem. Soc. 1996, 118, 2744.

71. Anderson, N. H.; Liu, Z.; Prickett, K. S. FEBS Lett. 1996, 399, 47.

72. Basu, G.; Kuki, A. Biopolymers 1993, 33, 995.

73. Fiori, W. R.; Miick, S. M.; Millhauser, G. L. Biochemistry 1993, 32, 11957.

74. Miick, S. M.; Martinez, G. V.; Fiori, W. R.; Todd, A. P.; Millhauser, G. L. Nature (London) 1992, 359, 653.

75. Toniolo, C.; Valente, E.; Formaggio, F.; Crisma, M.; Pilloni, G.; Corvaja, C.; Toffilette, A.; Martinez, G. V.; Hanson, M. P.; Millhauser, G. L.; George, C.; FlippenAnderson, J. L. J. Pept. Sci. 1995, 1, 45.

76. Balaram, P. Pure Appl. Chem. 1992, 64, 1061.

77. Paul, P. K. C.; Sukumar, M.; Bardi, R.; Piazzesi, A. M.; Valle, G.; Toniolo, C.; Balaram, P J. Am. Chem. Soc. 1986, $108,6363$.

78. Benedetti, E.; Di Blasio, B.; Pavone, V.; Pedone, C.; Santini, A.; Crisma, M.; Valle, G.; Toniolo, C. Biopolymers 1989, 28, 175

79. Pavone, V.; Benedetti, E.; Barone, V.; Di Blasio, B.; Lelj, F.; Pedone, C.; Santini, A., Crisma, M.; Bonora, G. M.; Toniolo, C. Macromolecules 1988, 21, 2064.

80. Bardi, R.; Piazzesi, A. M.; Toniolo, C.; Sukumar, M.; Balaram, P. Biopolymers 1986, 25, 1635.

81. Valle, G.; Crisma, M.; Toniolo, C. Can. J. Chem. 1988 , $66,2575$.

82. Valle, G.; Crisma, M.; Toniolo, C.; Sudhanand.; Rao, R. B.; Sukumar, M.; Balaram, P. Int. J. Peptide Protein Res. 1991, 38, 511

83. Benedetti, E.; Toniolo, C.; Hardy, P. M.; Barone, V.; Bavoso, A.; Di Blasio, B.; Grimaldi, P.; Lelj, F.; Pavone, V.; Pedone, C.; Bonora, G. M.; Lingham, I. L. J. Am. Chem. Soc. 1984, 106, 8146.

84. Barone, V.; Lelj, F.; Bavoso, A.; Di Blasio, B.; Grimaldi, P.; Pavone, V.; Pedone, C. Biopolymers 1985, 24, 1759.

85. Benedetti, E.; Barone, V.; Bavoso, A.; Di Blasio, B.; Lelj, F.; Pavone, V.; Pedone, C.; Bonora, G. M.; Toniolo, C.; Leplawy, M. T.; Kaczmarek, K.; Redlinski, A. Biopolymers 1988, 27, 357.

86. Bonora, G. M.; Toniolo, C.; Di Blasio, B.; Pavone, V.; Pedone, C.; Benedetti, E.; Lingham. I. L.; Hardy, P. M. J. Am. Chem. Soc. 1984, 106, 8152.

87. Toniolo, C.; Bonora, G. M.; Bavoso, A.; Benedetti, E.; Di Blasio, B.; Pavone, V.; Pedone, C., Barone, V.; Lelj, F.; Leplawy, M. T.; Kaczmarek, K.; Redlinski, A. Biopolymers 1988, 27, 373 .

88. Dentino, A. R.; Pavone, V.; Raj, P. A.; Bhandary, K. K.; Wilson, M. E.; Levine, M. J. J. Biol. Chem. 1991, 266, 18460. 89. Prasad S.; Mitra S.; Subramanian, E.; Velmurugan, D.; Rao, R. B.; Balaram. P. Biochem. Biophys. Res. Commun. 1994, 198, 424.

90. DiBlasio, B.; Pavone, V.; Isernia, C.; Pedone C.; Benedetti, E.; Toniolo, C.; Hardy, P.; M.; Lingham, I. J. Chem. Soc, Perkin Trans. 2 1992, 523.

91. Karle, I. L.; Rao R. B.; Prasad, S.; Kaul, R.; Balaram, P. J. Am. Chem. Soc. 1994, 116, 10355.

92. Karle, I. L.; Gurunath, R.; Prasad, S.; Kaul, R.; Rao R. B.; Balaram, P. J. Am. Chem. Soc. 1995, 117, 9632.

93. Karle, I. L.; Rao R. B.; Kaul, R.; Prasad, S.; Balaram, P. Biopolymers 1996, 39, 75.

94. Karle, I. L.; Gurunath, R.; Prasad, S.; Rao, R. B.; Balaram, P. Int. J. Peptide Protein Res. 1996, 47, 376. 
95. Karle, I. L.; Kaul, R.; Ragothama, S.; Rao, R. B.; Balaram, P. J. Am. Chem. Soc. 1997, 119, 12048.

96. Datta, S.; Kaul, R.; Rao, R. B.; Shamala, N.; Balaram, P. J. Chem. Soc., Perkin Trans. 2 1997, 1659.

97. Prasad, S.; Rao, R. B.; Bergstrand, H.; Lundquist, B.; Becker, E. L.; Balaram, P. Int. J. Peptide Protein Res. 1996, $48,312$.

98. Efimov, A. V. FEBS Lett. 1984, 166, 33.

99. Srinivasan, N.; Sowdhamini, R.; Ramakrishnan, C.; Balaram, P. In Molecular Conformation and Biological Interactions; Balaram, P.; Ramaseshan, S., Eds.; Indian Academy of Sciences: Bangalore, 1991; pp 59-73.

100. Fezoui, Y.; Weaver, D. L.; Osterhout, J. J. Protein Sci. 1995, 4, 286.

101. Olofsson, S.; Johansson, G.; Baltzer, L. J. Chem. Soc., Perkin Trans 2 1995, 2047.

102. Brive, L.; Dolphin, G. T.; Baltzer, L. J. Am. Chem. Soc. 1997, 119, 8598 .

103. Karle, I. L.; Flippen-Anderson, J.; Sukumar, M.; Uma, K.; Balaram, P. J. Am. Chem. Soc. 1991, 113, 3952.

104. Karle, I. L.; Banerjee, A.; Balaram, P. Folding Design 1997, 2, 203.

105. Banerjee, A.; Ragothama, S.; Balaram, P. J. Chem. Soc., Perkin Trans. 2 1997, 2087.

106. Gurunath, R.; Balaram, P. Biochem. Biophys. Res. Commun. 1994, 202, 241.

107. Schellman, C. In Protein Folding; Jaenicke, R., Ed.; Elsevier: North Holland Amsterdam, 1980; pp 53-61.

108. Milner-White, E. J. J. Mol. Biol. 1988, 199, 503.

109. Nagarajaram, H. A.; Sowdhamini, R.; Ramakrishnan, C.; Balaram, P. FEBS Lett. 1993, 321, 79.

110. Aurora, R.; Srinivasan, R.; Rose, G. D. Science 1994, 264, 1126.

111. Banerjee, A.; Datta, S.; Pramanik, A.; Shamala, N.; Balaram, P. J. Am. Chem. Soc. 1996, 118, 9477.

112. Datta, S.; Shamala, N.; Banerjee, A.; Pramanik, A.; Bhattacharjya, S.; Balaram, P. J. Am. Chem. Soc. 1997, 119, 9246.

113. Gunasekaran, K.; Nagarajaram, H. A.; Ramakrishnan, C.; Balaram, P. J. Mol. Biol. 1998, 275, 917.

114. Sibanda, B. L.; Thornton, J. M. Nature (London) 1985, $316,170$.

115. Milner-White, E. J.; Poet, R. Biochem. J. 1986, 240, 289.
116. Sibanda, B. L.; Blundell, T. L.; Thornton, J. M. J. Mol. Biol. 1989, 206, 759.

117. Gunasekaran, K.; Ramakrishnan, C.; Balaram, P. Protein Eng. 1997, 10, 1131.

118. Awasthi, S. K.; Raghothama, S.; Balaram, P. Biochem. Biophys. Res. Commun. 1995, 216, 375.

119. Karle, I. L.; Awasthi, S. K.; Balaram, P. Proc. Natl. Acad. Sci. USA 1996, 93, 8189.

120. Raghothama, S. R.; Awasthi, S. K.; Balaram, P. J. Chem. Soc., Perkin Trans. 2 1998, 137.

121. Struthers, M. D.; Cheng, R. P.; Imperiali, B. Science 1996, 271, 342.

122. Struthers, M. D.; Cheng, R. P.; Imperiali, B. J. Am. Chem. Soc. 1996, 118, 3073.

123. Haque, T. S.; Little, J. C.; Gellman, S. H. J. Am. Chem. Soc. 1994, 116, 4105.

124. Haque, T. S.; Gellman, S. H. J. Am. Chem. Soc. 1997, 119, 2303.

125. Das, C.; Raghothama, S.; Balaram, P. J. Am. Chem. Soc. 1998, 120, 5812.

126. Ramirez-Alvardo, M.; Blanco, F. J.; Serrano, L. Nat. Struct. Biol. 1996, 3, 604.

127. Stanger, H. E.; Gellman, S. H. J. Am. Chem. Soc. 1998, 120, 4236.

128. Kortemme, T.; Ramirez-Alvardo, M.; Serrano, L. Science 1998, 281, 253.

129. Schultz, G. E. Curr. Opin. Struct. Biol. 1996, 6, 485.

130. Budt, K. H.; Vatele, J. M.; Kishi, Y. J. Am. Chem. Soc. 1986, 108,6080 .

131. Basu, G.; Kubasik, M.; Anglos, D.; Secor, B.; Kuki, A. J. Am. Chem. Soc. 1990, 112, 9410.

132. Batchelder, T. L.; Fox, III, R. J.; Meier, M. S.; Fox, M. A. J. Org. Chem, 1996, 61, 4206.

133. Fox, M. A.; Galoppini, E. J. Am. Chem. Soc. 1997, 119, 5277.

134. Otoda, K.; Kimura, S.; Imanishi, Y. J. Chem. Soc., Perkin Trans. 2, 1993, 3011.

135. Fujita, K.; Kimura, S.; Imanishi, Y. J. Am. Chem. Soc. 1994, 116, 2185.

136. Cormack, P. A. G.; Sherrington, D. C.; Moore, B. D. J. Materials Chem. 1997, 7, 1977.

137. Strong, A. E.; Moore, B. D. J. Chem Soc., Chem. Commun. 1998, 473. 